\title{
A não-modernidade de Bruno Latour e suas implicações para a Educação em Ciências ${ }^{+}$
}

Nathan Willig Lima ${ }^{1}$

Fernanda Ostermann ${ }^{1}$

Claudio Jose de Holanda Cavalcanti ${ }^{1}$

Instituto de Física - Universidade Federal do Rio Grande do Sul

Porto Alegre - RS

\section{Resumo}

Neste trabalho, propomos a visão não-moderna de Bruno Latour como referencial teórico para fundamentar a Educação em Ciências. Apresentamos os conceitos basilares de sua teoria, partindo da Antropologia Simétrica e suas implicações ontológicas. À luz de conceitos como híbridos, redes, mediação e purificação, explicamos o seu posicionamento "não-moderno" e interpretamos conclusões polêmicas de A Vida de Laboratório. Trazemos, por fim, uma discussão sobre implicações da visão de Latour para a área da Educação em Ciências, sugerindo quatro pontos principais: a abordagem da ciência em ação, a preocupação com o processo de formação das teorias científicas e não somente a apresentação das teorias "prontas", a problematização das redes sociotécnicas e a formação de uma comunidade de leitores escritores.

Palavras-chave: Latour; Antropologia Simétrica; Sociocultural.

\begin{abstract}
In this work, we propose Bruno Latour's non-modern view as theoretical framework for Science Education. We present fundamental concepts of his theory, departing from the Symmetrical Anthropology and its ontological implications. In the light of concepts such as hybrid,
\end{abstract}

\footnotetext{
${ }^{+}$Bruno Latour's non-modernity and its implications to Science Education

* Recebido: julho de 2017.

Aceito: março de 2018.

1 E-mails: lima.nathan@gmail.com; 00008943@ufrgs.br; claudio.cavalcanti@ufrgs.br
} 
networks, mediation and purification, we explain his "non-modern" point of view and we interpret the controversial conclusions of "Laboratory Life". Finally, we introduce a debate on Latour's vision implications to Science Education by pointing out four major ideas: the approach of science in action, the concern about the process of building up theories instead of only presenting their final description, the problematization of sociotechnical networks and the formation of a reader-writer community.

Keywords: Latour; Symmetrical Anthropology; Sociocultural.

\section{Introdução}

Bruno Latour (1947-) é um filósofo e antropólogo francês que, após anos de estudos de campo na África, especializou-se em analisar cientistas e engenheiros em seu local de trabalho (LATOUR, 2017). Embora seu trabalho não abarque diretamente questões de Educação em Ciências, mantendo-se circunscrito principalmente à análise de ciências empíricas, na literatura em Educação em Ciências, suas ideias são introduzidas em diversos artigos. Stetsenko (2008), por exemplo, discute, em consonância com Latour, a necessidade de a Perspectiva Sociocultural romper com a ontologia kantiana, que separa os objetos-em-si dos sujeitos cognoscentes, passando para uma ontologia da relação. Ainda dentro da Perspectiva Sociocultural, o rompimento de Latour com a ontologia moderna e a superação da epistemologia moderna por Vygotski ${ }^{2}$ podem indicar a possibilidade de proximidades teóricas entre os dois autores. O conceito de mediação, por exemplo, é detalhadamente explorado por ambos e tal intersecção já foi discutida na literatura em Educação (MELO, 2010).

A literatura também lança mão da obra de Bruno Latour para discutir diferentes questões da Educação (BARNACLE; MEWBURN, 2010; ELLIOTT; YOUNG, 2015; KIRCH; MA, 2016), uso da linguagem (DODICK et al., 2008; GIL-SALOM; SOLERMONREAL, 2009; TAKAO; KELLY, 2003), problemas ambientais e de sustentabilidade (COLUCCI-GRAY, 2014; IORIO et al., 2017; PALHARINI, 2012), e questões póscolonialistas e feministas (ALSOP; FAWCETT, 2010; SOLBRÆKKE et al., 2013). Apesar de essas publicações tratarem de temas extremamente importantes em que a obra de Latour pode apresentar uma profícua contribuição, muitas delas não atingem aquilo que Latour julga ser o coração de sua contribuição para a área, sua perspectiva ontológica, a possibilidade de se olhar para a natureza simetricamente à sociedade.

Em particular, pode-se notar que, quanto mais específicos e técnicos os temas das revistas da área de Educação ou Ensino, menor a probabilidade de se encontrar artigos que tra-

\footnotetext{
2 Do ponto de vista puramente epistemológico, a obra de Vygotski pode ser entendida como uma síntese dialética das propostas absolutistas (racionalismo e empirismo) (WERTSCH, 1992).
} 
gam a obra de Latour. Em particular, em Ensino de Física, não existe nenhum artigo que o mencione na Revista Brasileira de Ensino de Física ou no Caderno Brasileiro de Ensino de Física (pesquisa feita no dia 28 de abril de 2017). Isso mostra, claramente, que a área de Educação em Ciências ainda não chegou ao cerne do trabalho de Latour: seu debate ontológico.

Diferentemente de epistemólogos que prescrevem o que deve ser a ciência (BUNGE, 2013; LAKATOS, 1984; POPPER, 2008), ou daqueles que analisam acontecimentos científicos em um passado remoto (KUHN, 1978), Latour se debruça sobre a ciência viva, dos nossos dias, em construção, em ação (LATOUR, 2011). Em suas obras, não existe a preocupação em estabelecer argumentos apriorísticos sobre o que é a ciência, tão pouco as próprias afirmações dos cientistas são levadas como se fossem verdades incontestáveis (LATOUR; WOOLGAR, 1988).

Sua contribuição revolucionária para o estudo da natureza da ciência está em tê-la tornado objeto de estudo da Antropologia e, portanto, passível de ser avaliada em campo. Nesse sentido, parece que Latour encarna em seu método de trabalho o próprio espírito científico bachelariano (BACHELARD, 1978; 1996): tomando a ciência como objeto de estudo, não confia cegamente no que os outros dizem, é crítico a tudo que ouve e lê e confronta suas próprias visões com observações empíricas.

No legado latouriano, o estudo da ciência é feito pela mão do antropólogo que, dentro do laboratório, avalia minuciosamente o comportamento dessa estranha tribo chamada de neuroendocrinologistas (LATOUR; WOOLGAR, 1988; 1997). O ponto de partida de Latour, entretanto, é mais complexo e ousado do que pode parecer para o leitor incauto e alheio ao debate sociológico da última metade do século XX. Uma leitura apressada ou superficial do livro A Vida de Laboratório tem conduzido a uma série de ataques despropositados (CREF, 2014; SLEZAK, 1984; SOKAN; BRICMONT, 2010). Primeiramente, classificam Latour como um pós-moderno, o que, como discutiremos na seção 4, não está de acordo com sua obra. Além disso, sua controversa afirmação de que os fatos científicos são socialmente construídos, por exemplo, tem sido interpretada como se as afirmações científicas não diferissem das afirmações presentes na literatura de ficção. Certamente, não é isso que Latour quis dizer (LATOUR, 1988, p. 29) conforme discutiremos na seção 5.

Antes de adentrarmos em questões da natureza da ciência, devemos ter em mente que o seu pensamento traz pressupostos de caráter ontológico, os quais não podem ser subestimados. A sua visão não-moderna (LATOUR, 2013) está diretamente ligada à natureza da realidade: Latour propõe uma ruptura com as construções ontológicas da sociedade moderna (a dizer, ele contradiz a separação entre natureza e sociedade), inviabilizando o pretenso ideal de corte epistemológico de Bachelard. Devemos levar em consideração, por outro lado, que ele também confronta o programa forte de Bloor (BLOOR, 1982), cujo objetivo é reduzir conhecimento científico a uma construção social.

Neste trabalho, temos o objetivo de apresentar os fundamentos ontológicos da visão de Bruno Latour, partindo da Antropologia Simétrica (seção 2). Apresentamos o conceito de 
híbridos e redes (seção 3), e problematizamos os conceitos de modernidade, pós-modernidade e não modernidade (seção 4) indicando o que Latour aceita e rejeita de cada visão. Ainda nessa seção, apresentaremos o conceito de mediação e purificação. Na seção 5, interpretamos o livro A Vida de Laboratório (seção 5) à luz das seções anteriores. Finalmente, fazemos uma proposta do uso das ideias de Latour como referencial para a Educação em Ciências (seção 6).

\section{A antropológica simétrica}

A Antropologia (STRAUSS, 1962; 1987) tem se dedicado extensivamente a estudar tribos remotas, costumes exóticos, relações familiares e cultos extremamente complexos e distantes. Ao fazê-lo, o etnólogo não escreve três livros diferentes (um sobre a cultura, um sobre os conhecimentos e um sobre o poder) (LATOUR, 2013, p. 20) - ele escreve um só relato, um único texto sobre o coletivo natureza-cultura.

Ao se voltarem para a sociedade moderna, esses mesmos etnólogos optaram por analisar os seus costumes populares, as representações simbólicas, os marginais - tudo aquilo que não pertence ao "mundo moderno". Antes de Bruno Latour, a Antropologia não havia dito uma só palavra sobre a ciência, a indústria, a técnica (LATOUR; WOOLGAR, 1988). Dessa forma, mesmo a Antropologia do mundo ocidental, antes de Latour, havia decidido olhar apenas para a parte "não-moderna" de nossa cultura. Essa escolha não é arbitrária; mas reflete a premissa teórica de que o mundo moderno não poderia ser objeto da Antropologia visto que ele rompeu os laços entre cultura e natureza.

Nos anos 60 e 70 do século XX, surgiu, entretanto, uma série de estudos sobre a ciência em seu contexto social. Os dois polos ontológicos ("natureza" e "sociedade"), entretanto, seguiram misturados como água e óleo em repouso (LATOUR; WOOLGAR, 1988), indicando a perpetuação da premissa teórica supracitada: a Antropologia pode estudar as outras civilizações; mas não a nossa. E, quando estuda a nossa, pode investigar o que é místico, popular, simbólico, mas não o que é científico e técnico. A assimetria antropológica entre "outros" e "nós" é apenas uma consequência da assimetria da ontológica acerca da "sociedade" e da "natureza" na civilização moderna. É essa assimetria ontológica que Latour reconhece em sua obra.

Nesse contexto, os primeiros estudos sociológicos da ciência usavam a "sociedade" para explicar as intenções do cientista, suas crenças, sua ação política e social, mas não o produto final que ele produzia (LATOUR; WOOLGAR, 1988). Aliás, a sociologia poderia explicar os erros do cientista, como suas visões subjetivas, o afastaram da realidade. Os acertos (o conteúdo científico), por outro lado, escapariam da análise sociológica visto que seriam frutos da natureza e, portanto, independentes do social, reificando o tão almejado sonho de Gaston Bachelard em sua Filosofia do Não (BACHELARD, 1978).

O Primeiro Princípio de Simetria foi proposto na década de 80 do século passado, por Bloor (BLOOR, 1982) em seu Programa Forte da Sociologia, cujo objetivo seria explicar não só os erros, mas também os acertos da ciência através da sociologia. Ou seja, para essa 
concepção, todo o conhecimento científico poderia ter uma explicação social. O princípio é considerado simétrico, pois posiciona a sociedade de forma equidistante aos erros e aos acertos científicos. Deve-se notar que essa visão é diametralmente oposta à proposta de Bachelard. Muitos dos críticos de Latour o associam ao programa forte de Bloor; mas estão equivocados na medida em que Latour afasta-se do Primeiro Princípio de Simetria propondo a necessidade de redefinir o conceito de Sociedade (LATOUR, 1999; 2005).

O afastamento de Latour com relação ao Programa Forte da Sociologia se deve ao reconhecimento da persistência de um pensamento assimétrico na visão blooriana. Embora Bloor seja construtivista para a natureza (os achados científicos são sociologicamente construídos) ele é realista para a sociedade. Isto é, ao dizer que podemos explicar a ciência pela Sociedade, estamos reificando essa "entidade", considerando que a conhecemos a priori como ela de fato é. Entretanto, se a natureza é construída socialmente, o que se dirá da própria sociedade?

Latour, opondo-se ao Programa Forte, adere ao Princípio de Simetria Generalizado, propondo-se a explicar a natureza e a sociedade sem tomá-las como polos ontológicos distintos. De acordo com o filósofo francês, precisamos nos posicionar de tal forma que nem a natureza nem a sociedade sejam entendidas como inerentemente existentes a priori.

Tomemos como exemplo a proposta da natureza quântica da radiação de Einstein (1905). Pela visão epistemológica de Bachelard, os erros de Einstein podem ser entendidos socialmente. No entanto, a previsão correta para a equação do efeito fotoelétrico (o conteúdo do artigo) não pode ser explicado sociologicamente; mas sim pela natureza. Nessa assimetria explicativa repousa a própria assimetria ontológica atribuída à natureza e à sociedade (Figura 1a). À luz do primeiro Princípio de Simetria, por outro lado, poderíamos estudar a sociedade alemã do início do século XX, e, a partir dela, explicar a equação de Einstein usando conceitos como classes, grupos, poder (LATOUR, 1988). Poderíamos mostrar como o próprio conteúdo da equação se funde com elementos intrinsicamente sociais (figura 1b). Esse foi o caminho seguido, por exemplo, no interessante estudo sobre o embate intelectual entre Boyle e Hobbes sobre a bomba de vácuo (SHAPIN; SCHAFFER, 1985). Nessa obra, os autores mostram como que o grupo de pesquisadores do qual Boyle faz parte funda a nova práxis científica (empirista) viabilizando a construção do conceito de vácuo e, ao mesmo tempo, interferindo na ordem social britânica.

Latour aponta, entretanto, que, para explicar o "contexto" de Boyle (ou de Einstein, ou de qualquer outro exemplo), precisamos "ler" outros "textos". Não temos acesso à realidade social direta de Boyle. Assim, não existe um contexto real, reificável, palpável e a acessível a nós. O que existem são "co-textos", os quais, como quaisquer textos, possuem pontos de vista, reflexões e refrações da realidade (BAKHTIN, 2016).

Como, então, ser simétrico sem recair na objetivação de nenhum dos polos ontológicos? Isto é, sem atribuir à natureza e à sociedade uma essência objetiva? O ponto de partida deve ser invertido. Ao invés de partir da natureza e da sociedade para explicar acerto e erro 
(epistemologia bachelariana) ou partir da sociedade para explicar tudo (programa blooriano), devemos partir do efeito fotoelétrico para explicar a natureza e a sociedade. Devemos nos perguntar o que aprendemos do artigo de Einstein sobre a sociedade, sobre a sociologia e a natureza (LATOUR, 1988). Como o artigo de Einstein redefine a sociedade e natureza? A quantização da radiação eletromagnética não é mais aquilo que queremos explicar, ele é a fonte das explicações (Fig. 1c).

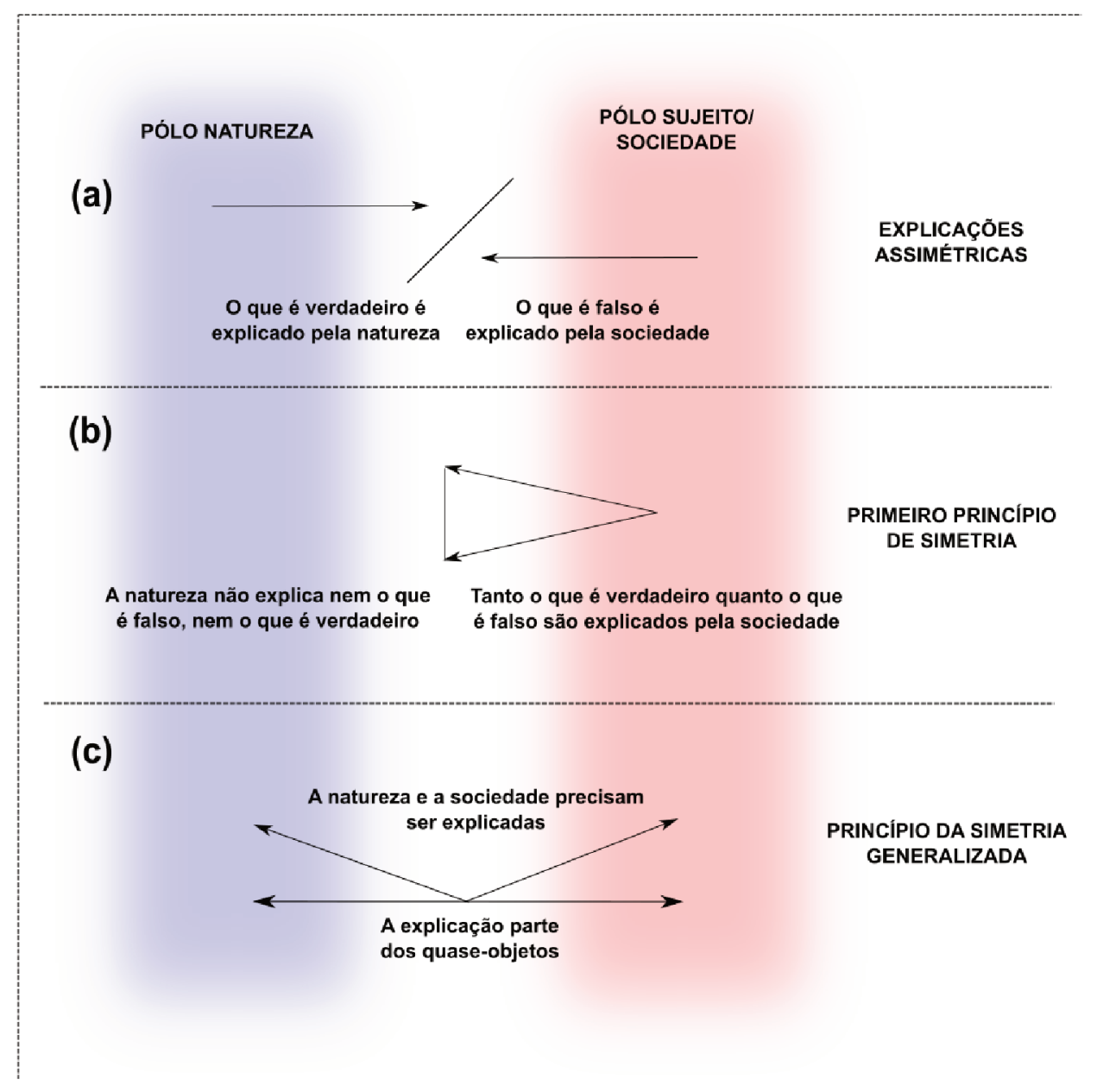

Fig. 1. (a) A visão epistemológica (Bachelard) explica os erros da ciência pelo contexto social, enquanto que a natureza explica os acertos. (b) A visão de Bloor usa a sociedade para explicar os erros e os acertos da ciência. (c) A visão simétrica generalizada usa a produção científica para explicar a natureza e a sociedade. Figura adaptada da obra Jamais Fomos Modernos (LATOUR, 2013).

Assim, para Latour, não devemos mais pensar na existência de uma natureza e de uma sociedade independentes que podem ser usadas como fonte de explicação das coisas. Pelo contrário, devemos olhar para os quase-objetos ou os híbridos e, a partir deles, rastrear empiricamente a rede sociotécnica que os cercam e, a partir disso, entender a construção da sociedade e da natureza. 


\section{Híbridos, redes e o problema ontológico}

No livro Jamais Fomos Modernos, Latour traz o exemplo dos buracos na camada de ozônio (LATOUR, 2013). A pergunta que o antropólogo almeja responder é se esses objetos são reais e independentes da sociedade e do discurso, ou se estamos apenas falando de estruturas socialmente construídas e artificiais, ou, ainda, se estamos falando apenas de efeitos do discurso. Sua resposta é não para as três opções:

O buraco de ozônio é por demais social e por demais narrado para ser realmente natural; as estratégias das firmas e dos chefes de Estado, demasiado cheias de reações químicas para serem reduzidas ao poder e ao interesse; o discurso da ecoesfera, por demais real e social para ser reduzido a efeitos de sentido. Será nossa culpa se as redes são ao mesmo tempo reais como a natureza, narradas como o discurso, coletivas como a sociedade? (Latour, 2013, p.12)

O cientista, no laboratório, articula híbridos. Ninguém subiu até a camada de ozônio e constatou com seus próprios olhos a existência de buracos e sua formação sendo causada por agentes antropogênicos. As conclusões obtidas pelos cientistas são frutos de interpretações de inscrições de equipamento à luz e de debates científicos e políticos. Existe uma rede de atores, humanos e não humanos, interagindo para produzir esses conhecimentos. Quando falamos de buracos na camada de Ozônio, estamos falando de um híbrido que surge da interação entre cientistas, equipamentos, políticos, sociedade, isto é, da interação de uma rede sociotécnica. Sua constituição é social, mas não é só social, é fruto de efeitos do discurso, mas não só isso; é também resultado de reações químicas naturais, mas não pode ser reduzida a elas.

Caso semelhante pode ser identificado com relação ao TRF (Hormônio Liberador de Tireotrofina): os neuroendocrinologistas não olharam diretamente para a molécula com seus olhos. Eles interpretaram inscritores resultantes de experimentos à luz de uma série de outros discursos. A articulação do TRF, portanto, envolve elementos que são intrinsicamente discursivos e sociais. Não estão alheios a uma rede de disputas políticas e intelectuais; não podendo, entretanto, ser reduzido ao social e ao discursivo. O TRF é um híbrido construído pela rede de cientistas, teorias, equipamentos e técnicas que o cercam. Da mesma forma, o quantum de Einstein é um híbrido! A função de onda de Schrödinger é um híbrido. O espaço-tempo de Einstein é um híbrido.

O cientista, entretanto, nega a dimensão social e discursiva do objeto que ele articula e nega a formação de uma rede sociotécnica ao redor desse híbrido. Ele constrói o TRF, ele monta sua amostra, usa equipamentos, obtém inscrições, as interpreta à luz de teorias discursivas e, depois, diz que o TRF sempre esteve lá independentemente de seu trabalho. É como se a natureza, apesar de ser constantemente construída pelo cientista, funcionasse como se fosse independente dele. Deve-se ter o cuidado, entretanto, para não confundir a ideia de que, por serem construídos, os fatos são fictícios. Pelo contrário, é porque os construímos que ga- 
rantimos sua existência. Quanto mais construímos um ente, mais real ele se torna (LATOUR, 1999). Essa existência, entretanto, não é independente da rede que o criou. Não existe, para Latour, uma separação objetiva entre natureza e sociedade. É através da rede e sua interação que sociedade e natureza são construídas em conjunto. Esse abismo ontológico, que hoje nos é tão comum, é fruto de uma construção artificial da modernidade.

\section{A Modernidade, a Pós Modernidade e a não-Modernidade}

Para entender por que a sociedade e a natureza nos parecem, hoje, tão distantes, precisamos analisar como tal visão de mundo foi criada na modernidade. Suas bases filosóficas poderiam ser recuperadas na proposta platônica de separar o mundo das Ideias da realidade material. No mundo moderno, entretanto, o corte entre natureza e sociedade é estabelecido na filosofia cartesiana e intensificada na proposta de Kant, segundo a qual a coisa-em-si se mantém sempre inacessível a um sujeito cognoscente, que somente pode a tangenciar pela mediação do fenômeno (LATOUR, 1999). Latour, por outro lado, se opõe à ruptura entre natureza e sociedade expressa seja por Platão, Descartes ou Kant. Em síntese, sua proposta pode ser entendida como uma extensão do princípio existencialista de Sartre, segundo o qual existência antecede essência ${ }^{3}$ (LATOUR, 2013). Ou, ainda que Latour critique a fenomenologia, sua proposta pode ser entendida como uma retomada da noção heideggeriana de que o Ser é um processo, uma atividade e não um ente (HARMAN, 2009). Para Latour, o buraco da camada de ozônio, o TRF, ou qualquer outro actante está em um constante processo de articulação. Sua existência nunca é dada e garantida; mas continuamente sustentada pelo esforço de articulação da sua rede (LATOUR, 2005).

Latour descreve a proposta modernizadora, descrevendo as quatro premissas sobre as quais ela se funda: 1) aceitamos uma natureza transcendente, 2) acreditamos em uma sociedade imanente, 3) negamos a existência dos híbridos e 4) expurgarmos Deus da realidade. São essas quatro premissas que nos distinguem de todas outras civilizações e que nos separam de nossos antepassados pré-modernos. Fomos capazes de acreditar na separação entre natureza e sociedade e, assim, imaginar ser capazes de desenvolver um conhecimento natural e independente de tudo que é social, subjetivo e religioso (LATOUR, 2013).

Tais premissas fundam o que Latour chama de dois paradoxos e a Constituição da Modernidade (tabela 1). O primeiro paradoxo indica que tratamos a natureza como se essa fosse transcendente e alheia a nós enquanto que a sociedade é considerada fruto de nossa vontade. No segundo paradoxo, a sociedade moderna vale-se justamente do posicionamento con-

\footnotetext{
3 A discussão sobre a existência e a essência remonta a Aristóteles (NELSON, 2012), para o qual ambas eram indissociáveis. Tal concepção é combatida por São Tomás de Aquino (AQUINO, 1995), que afirmava a essência preceder a existência, visto que é possível conceber a essência de um ente que não existe. Sartre, por sua vez, deriva da inexistência de Deus que, pelo menos, os homens têm sua existência anterior à essência, visto que não foram concebidos antes de existir (SARTRE, 2007). Ao estender as propriedades dos humanos aos não humanos, Latour aplica o princípio existencialista de Sartre (a existência antecede a essência) para os "fatos científicos" (LATOUR, 2013).
} 
trário: ela constrói a natureza no laboratório e subordina-se à estrutura social. Ambos os paradoxos conduzem à constituição da modernidade. A primeira garantia oferecida pela Constituição é que, ainda que sejamos nós que construímos a natureza, ela funciona como se não a construíssemos. A segunda garantia oferecida pela Constituição é que, ainda que não sejamos nós que construímos a sociedade, ela funciona como se nós a construíssemos. E, por fim, a terceira garantia trata da separação entre dois tipos de práticas: purificação e mediação.

A mediação (ou tradução) é justamente o processo de criação dos híbridos, é a interação entre os diferentes atores da rede. Quando um cientista experimental escreve um artigo, ele está "traduzindo" (ou mediando) o que o aparelho "quer dizer". Os fatos são mudos e os cientistas falam por eles, os traduzem; mas ao fazer isso, criam híbridos de ciência, natureza e sociedade. A purificação, por outro lado, interage com o híbrido para separar (partindo do pressuposto que isso é possível) o que "pertence" a cada polo ontológico. Com essa suposta separação, a sociedade moderna alcançou feitos que nenhuma outra civilização alcançou: a natureza transcendente nos garante que possamos construí-la no laboratório e, ainda sim, afirmar que ela existe independentemente de nós. A sociedade imanente permite que acreditemos que somos nós os construtores da nossa realidade social, embora, na prática, estejamos fortemente delimitados por ela. A negação dos híbridos permite-nos ir para os laboratórios acreditando que nada do que fazemos interfere na ordem social e política e, somente ao fazer isso, é que permitimos a sua proliferação. Ao expurgar Deus, transladamos a fonte de verdade e de poder da religião para ciência e somos capazes de reestabelecer a ordem social e científica.

Tabela 1 - Paradoxos e Constituição Moderna. Adaptado de Latour (2013).

\begin{tabular}{|c|c|}
\hline \multicolumn{2}{|c|}{ Primeiro Paradoxo } \\
\hline $\begin{array}{l}\text { A natureza não é uma construção nossa: ela } \\
\text { é transcendente e nos ultrapassa infinita- } \\
\text { mente. }\end{array}$ & $\begin{array}{l}\text { A sociedade é uma construção nossa: ela } \\
\text { é imanente à nossa ação. }\end{array}$ \\
\hline \multicolumn{2}{|c|}{ Segundo Paradoxo } \\
\hline $\begin{array}{l}\text { Nós construímos a natureza artificialmente } \\
\text { no laboratório. Ela é imanente. }\end{array}$ & $\begin{array}{l}\text { Não construímos a sociedade. Ela nos } \\
\text { ultrapassa infinitamente. }\end{array}$ \\
\hline \multicolumn{2}{|c|}{ Constituição } \\
\hline $\begin{array}{l}1^{\text {a }} \text { garantia: Ainda que sejamos nós que } \\
\text { construímos a natureza, ela funciona como } \\
\text { se não a construíssemos. }\end{array}$ & $\begin{array}{l}2^{a} \text { garantia: Ainda que não sejamos nós } \\
\text { que construímos a sociedade, ela funciona } \\
\text { como se nós a construíssemos. }\end{array}$ \\
\hline $3^{a}$ garantia: A natureza e a sociedade devem & rmanecer absolutamente distintas; o traba- \\
\hline
\end{tabular}


O problema é que essas duas práticas (mediação e purificação), na realidade, acontecem ao mesmo tempo; ainda que os modernos digam que não. O cientista vai ao laboratório e cria o TRF (um híbrido) através da mediação; mas anuncia no seu artigo que "descobriu" o TRF, uma substância natural e independente da sociedade e do discurso. Para purificar um híbrido, identificar sua parte natural, por exemplo, precisamos traduzir os resultados de um inscrito obtido com um equipamento. Com isso estamos hibridizando ainda mais natureza e sociedade. Jamais conseguimos fazer a prática de purificação sem usar a tradução.

Os modernos dizem que mediação e purificação são processos separados e independentes, pois é nisso que se baseia sua constituição. Ao observamos os cientistas trabalhando, vemos que não é isso que acontece. Mediação e purificação acontecem juntas - o cientista afirma fazer purificação, mas tudo que faz é tradução, e os híbridos se proliferam. Existe uma diferença, portanto, entre o que é a ciência oficiosa e a ciência oficial (LATOUR, 2013).

Aquilo que nos separa das outras civilizações, a distinção entre dois polos ontológicos independentes, é uma mera ilusão: nós jamais fomos modernos. O que nos torna diferente das outras civilizações não é o fato de que conseguimos, de fato, separar a natureza e a sociedade, mas acreditar nessa possibilidade. Ao fazê-lo, permitimo-nos expandir a proliferação de híbridos como nunca feito antes. Somos iguais às outras culturas porque jamais conseguimos escapar da mesma matriz antropológica, o tecido inteiriço de natureza-sociedade-discurso; mas somos diferentes porque mobilizamos mais atores do que jamais foi feito (LATOUR, 2013)

Com relação à natureza da ciência, especificamente, baseando-se no embate entre Hobbes e Boyle (SHAPIN; SCHAFFER, 1985), Latour mostra como que a proposição da "constituição" moderna foi construída num embate político-científico no século XVII, do qual o empirismo surgiu como vencedor. Até então, a validade de um argumento se dava por sua estrutura lógica, apriorística. Por outro lado, o método empírico de Boyle, apoiando-se numa paráfrase jurídica, aufere a grupos de pesquisadores a possibilidade de estabelecer verdades independentemente da estrutura apodítica. Com a vitória da tradição boyleana, entretanto, a ciência se afastou da episteme para se tornar doxa (LATOUR, 2013).

Latour mostra que o embate entre raciocínio apodítico e método empírico foi travado por Hobbes e Boyle no campo não só da ciência, mas da política. Natureza e sociedade não eram diferentes: se o rei representa os cidadãos, o cientista representa os objetos. Os posicionamentos são simétricos. A palavra "representação" é a mesma e, de fato, tem o mesmo significado nos dois casos. O rei pode falar pelos cidadãos, mas também pode trai-los; o mesmo acontece com o cientista. A quebra do coletivo em sociedade e natureza como polos ontológicos distintos e incomunicáveis proporcionou que a representação política parecesse, hoje, apartada da representação científica.

Já no contexto contemporâneo, a partir da década de sessenta do século XX, entretanto, os impactos da segunda guerra mundial, incluindo o avanço da ciência nuclear e sua inata miscigenação com interesses geopolíticos, bem como estudos ambientalistas (CARSON, 
1994) permitiram a formação de um contexto em que o ideal cientificista (e todos os mitos a ele atrelados) pudesse ser colocado sob investigação ${ }^{4}$. O surgimento de epistemologias não absolutistas como a visão apresentada na obra emblemática de Thomas Kuhn (1978) - "A Estrutura das Revoluções Científicas" - representa justamente a possibilidade de se pensar sobre a ciência fora da objetividade herdada das tradições platônicas. Na década de 90, ainda, as novas conferências ambientais explicitaram o fracasso do intento modernista de dominar a natureza, e o fim da União Soviética explicitou o fracasso modernista de acabar com a dominação do homem sobre o homem. Tal cenário permitiu a ascensão de um ideal pósmodernista, o qual aponta as limitações e fracassos do modernismo, recaindo, entretanto, num sentimento de impotência ao se deixar levar pela crença de que tudo pode ser resumido aos efeitos do discurso e que a natureza e a sociedade são polos que não podem ser reatados (LATOUR, 2013).

Por essa postura cética, Latour não se posiciona como pós-moderno. Ele não acredita na separação entre natureza e sociedade. A modernidade nunca existiu, logo, não há como se opor a ela. Por outro lado, se a modernidade de fato não existiu, significa que não há nada de bom em nossa cultura? Não aprendemos nada com a ciência? Não há nada a aprender? Muito pelo contrário. O que Latour propõe é a adoção de uma "verdadeira honestidade intelectual". Vamos sim celebrar a ciência, mas vamos admitir que existem híbridos. Vamos supor que existe uma natureza objetiva que tentamos explicar; não existe erro nisso, mas não sejamos ingênuos de imaginar que produzimos verdades absolutas em laboratório. A separação entre uma natureza objetiva e uma sociedade subjetiva é uma ferramenta, uma estratégia de trabalho, útil e que produz resultados profícuos; mas deve ser entendida como uma ferramenta, como um artifício. A propósito, a separação entre natureza e sociedade é simétrica à separação entre judiciário e executivo - ela existe apenas como uma abstração; na prática, existem complexas redes que emaranham judiciário e executivo. Ainda assim, sua separação oficial é útil na sociedade moderna. Não precisamos, portanto, abandonar a separação entre natureza e sociedade ou a divisão entre executivo e judiciário, desde que reconheçamos que ela é um artifício. Partindo dessa reflexão, Latour reconhece que dos grupos modernos, não-modernos e pós-modernos, há elementos que podemos conservar e rejeitar em benefício de nosso coletivo (o que está sintetizado na tabela 2).

Reconhecendo essas considerações ontológicas, o papel do sociólogo ou antropólogo da ciência não é estudar como os cientistas chegam a verdades ou como o método científico é diferente e privilegiado com relação aos outros métodos. O sociólogo debruça-se sobre as interações entre os diferentes atores que compõe a rede sociotécnica, ele estuda os emaranhamentos entre natureza e sociedade (de forma simétrica a como um cientista político estuda as relações entre executivo e judiciário), ele analisa a formação dos híbridos e como esses tensi-

\footnotetext{
4 Ainda que a consolidação da área seja motivada pelos resultados da Guerra, existem obras anteriores a esse período, como os trabalhos de Robert Merton. Ainda do ponto de vista filosófico, outros pensadores já haviam refletido sobre problemas correlatos como o próprio Marx e Heidegger.
} 
onam a rede ao seu redor. Partindo da Antropologia Simétrica, Latour estuda a ciência e suas redes, pesquisa a ciência viva, em ação.

Tabela 2 - Elementos que Latour conserva e rejeita de cada perspectiva. Adaptado de Latour (2013).

\begin{tabular}{|l|l|l|}
\hline Grupo & O que Latour conserva & O que Latour rejeita \\
\hline Modernos & $\begin{array}{l}\text { Redes extensas } \\
\text { Experimentação } \\
\text { Separação da natureza objetiva e } \\
\text { sociedade subjetiva }\end{array}$ & $\begin{array}{l}\text { Separação da natureza e da sociedade } \\
\text { Clandestinidade da mediação } \\
\text { Universalidade }\end{array}$ \\
\hline Pré-modernos & $\begin{array}{l}\text { Não separabilidade das coisas e e } \\
\text { dos signos } \\
\text { Multiplicação dos não humanos }\end{array}$ & $\begin{array}{l}\text { Obrigatoriedade de ligar sempre na- } \\
\text { tureza e sociedade }\end{array}$ \\
\hline Pós Modernos & $\begin{array}{l}\text { Desconstrução } \\
\text { Reflexividade } \\
\text { Desnaturalização }\end{array}$ & $\begin{array}{l}\text { Impotência } \\
\text { Crença no Modernismo }\end{array}$ \\
\hline
\end{tabular}

\section{Revisitando A Vida de Laboratório}

A partir da discussão ontológica e epistemológica traçada nas seções anteriores, conseguimos entender melhor o que Latour, de fato, fez em seu livro A Vida de Laboratório (LATOUR; WOOLGAR, 1988). Ao identificar a construção de um híbrido, o TRF, Latour acompanha a interação da rede sociotécnica que se desenvolve ao seu redor. Latour analisa como os diferentes atores (os cientistas, os técnicos, os equipamentos, o TRF) interagem nessa rede. E, a partir desse estudo, chega a conclusões sobre como se dá a prática científica, incluindo a noção de que o TRF é socialmente construído.

Isso quer dizer que o TRF é um artifício literário? Não! Quer dizer que ele só existe dentro da rede que o criou. Isso significa que ele não existe fora da rede. Se quisermos provar que ele existe em outro lugar, teremos que estender a rede até lá, incluindo os equipamentos e as teorias que usamos. O TRF passará a existir até onde a rede se estender. A ciência, portanto, pode ser considerada universal dentro da rede. Não existem, portanto, verdades absolutas e totalmente universais.

Também, a partir deste estudo etnográfico, podemos chegar a conclusões sobre o que é o trabalho científico. Os cientistas, de acordo com Latour, são uma tribo de leitores e escritores. Eles leem os artigos produzidos por outros laboratórios e produzem seus próprios escritos. A escrita científica, entretanto, é diferente da literatura ficcional (LATOUR, 1988). Para entender esse aspecto da atividade científica, entretanto, é necessário que se entenda quais as diferenças semióticas entre esses dois gêneros discursivos (BAKHTIN, 2016). 
No gênero ficcional, o autor fornece elementos narrativos cujo objetivo é criar no leitor a sensação de que aquilo que está lendo é algo real, sendo os elementos coerentes dentro da estrutura da narrativa chamados de referente interno do texto. Quando o narrador afirma, por exemplo, que a personagem principal encontrou uma lista com nome das pessoas assassinadas, o leitor tem a impressão de que essa lista já existia e ele está sendo informado sobre isso (LATOUR, 1988). Se o autor ainda informa ao leitor que essa lista existe e está na biblioteca de Londres podendo ser consultada, cria-se um referente externo (não mais interno) que o leitor pode, de fato, verificar. Ou seja, existem inscrições que podem ser verificadas e sobrepostas à narrativa de forma a aumentar a confiança na veracidade da narrativa.

Os cientistas distinguem-se por produzirem narrativas factuais em que apontam referentes externos para aumentar a confiança do leitor na veracidade do que dizem. Esses referentes externos são as inscrições obtidas pelos aparelhos do laboratório. Portanto, a confiabilidade da ciência reside na possibilidade de sobrepor os dados de um laboratório com o que está escrito na narrativa de outro cientista (LATOUR, 1988).

Usando conceitos da semiótica, Latour analisa um livro de Albert Einstein (LATOUR, 1988) para mostrar como que a narrativa da teoria da relatividade é construída para resguardar a sobreposição de dados entre diferentes referenciais - pois, como comentado, é sobre essa sobreposição que reside a confiabilidade científica. O trabalho de Einstein, portanto, é considerado um trabalho de cunho semiótico voltado para o estudo de um efeito narrativo chamado shifting in e out. Shifiting out é o recurso semiótico través do qual o narrador translada a atenção do leitor para outro cenário. Shifiting in é o processo inverso. Em um artigo, o autor pode dizer "o laboratório X encontrou tais dados" - isso é um processo de shifting out-"nós também encontramos esse resultado" - isso é um processo de shifiting in. No ideal de ciência que temos hoje, os dados de diferentes laboratórios devem ser consistentes - ou seja, o autor deve ser capaz de construir narrativas baseadas em recursos de shifting in e out. A Teoria da Relatividade Geral permite que esse recurso seja usado por qualquer referencial (inercial ou não) do Universo, visto que explicita a relação entre a métrica e a distribuição de energia. Esse problema epistemológico foi reconhecido pelo próprio Einstein em seu artigo original de 1916.

Esse é um exemplo de como se usar a simetria generalizada na prática. Normalmente, veríamos o trabalho de Einstein apenas como algo que fale da natureza. Latour explicita, entretanto, a dimensão discursiva (semiótica) do trabalho e, também, seu caráter social, visto que, ao sacrificar a universalidade da métrica do espaço-tempo, Einstein salva a universalidade da própria ciência.

Avançando no estudo da natureza da ciência, podemos dizer, então, que, a partir do uso de shifting in e shifting out, o autor de textos científicos garante a possibilidade de o leitor comparar as inscrições e aumentar, assim, a confiabilidade científica. Além disso, como o objetivo do cientista é convencer o leitor daquilo que está escrito, o autor se vale de estratégias discursivas típicas do gênero literário científico com essa finalidade. A esse respeito, apa- 
rece uma questão interessante: “A função da inscrição literária é conseguir persuadir os leitores, mas esses só ficam plenamente convencidos quando todas as fontes de persuasão parecem já ter desaparecido" (LATOUR; WOOLGAR, 1988).

Ademais, Latour constata que, quando querem convencer os outros cientistas de algo, os escritores precisam dizer como aquilo foi produzido. Enquanto não houver confiança suficiente da comunidade, os rastros de produção do fato ficam evidentes. Somente quando há um grau de confiança muito grande, as inscrições não precisam mais ser mencionadas. A partir desse momento, parece que aquilo sempre existiu de forma tácita: "Havia decorrido um período intermediário durante o qual um desenvolvimento progressivo tinha se produzido, transformando um debate animado em um fato instituído, não litigioso e que agora passava despercebido" (LATOUR; WOOLGAR, 1988).

Acompanhando esse período intermediário, Latour notou que os enunciados dos cientistas nos artigos e no laboratório poderiam ser classificados em cinco grupos, mostrados na tabela 3 .

Tabela 3. Tipos de Enunciados encontrados em um laboratório.

\begin{tabular}{|l|l|l|}
\hline Tipos de Enunciados & Exemplos \\
\hline Tipo 1 & Conjecturas & $\begin{array}{l}\text { Vamos supor que a radiação seja com- } \\
\text { posta por um conjunto de elementos dis- } \\
\text { cretos. }\end{array}$ \\
\hline Tipo 2 & $\begin{array}{l}\text { Modalidades que insistem na gene- } \\
\text { ralidade dos dados }\end{array}$ & $\begin{array}{l}\text { Podem-se interpretar alguns dados com a } \\
\text { quantização da radiação. }\end{array}$ \\
\hline Tipo 3 & $\begin{array}{l}\text { Modalidades: Enunciados sobre } \\
\text { Enunciados }\end{array}$ & $\begin{array}{l}\text { Einstein afirmou que a radiação é quanti- } \\
\text { zada. }\end{array}$ \\
\hline Tipo 4 & $\begin{array}{l}\text { Saber Aceito } \\
\text { A radiação é quantizada. }\end{array}$ \\
\hline Tipo 5 & $\begin{array}{l}\text { Fato tido como adquirido (não pre- } \\
\text { cisam ser expressos, raramente apa- } \\
\text { recem) }\end{array}$ & Os fótons foram absorvidos pelo gás. \\
\hline
\end{tabular}

Por fim, podemos concluir que cientistas são leitores-escritores que buscam escrever textos factuais, usando inscritores de equipamentos como referentes externos, com o objetivo de promover enunciados do tipo 1 ao status de enunciados do tipo 5 .

\section{Implicações para a Educação em Ciências}

Acreditamos que a visão de Latour sobre a atividade científica representaria uma verdadeira revolução na Educação em Ciências que praticamos. Da maneira como é concebida atualmente, tal formação alinha-se à visão moderna, a qual não sobrevive a uma análise 
mais profunda como discutido na seção 4. Existem quatro pontos nevrálgicos a serem levados em conta:

\section{VI.1 A Educação em Ciências deve mostrar a ciência em ação e não a ciência pronta - abrindo as caixas pretas}

A crença no corte epistemológico bachelariano tem levado o ensino a apresentar as teorias físicas hegemônicas como verdades objetivas, absolutas e óbvias. A educação em Ciências não mostra que as "verdades" foram construídas e ocuparam, em algum momento, um palco de disputas não só circunscrito à dimensão intelectual, mas que também envolveu esferas políticas.

Ao entender que os fatos científicos são híbridos, interessa-nos considerar como eles são articulados pela rede sociotécnica, o que implica que não devemos considerar as teorias como verdades prontas e fechadas, independente dos co-textos. Já é hora de o ensino abrir a caixa preta da Física (LATOUR, 2011) e mostrar como as teorias são construídas.

Por exemplo, o "Ensino Moderno" explica o que é o Efeito Fotoelétrico e, simplesmente, afirma que a quantização da radiação eletromagnética o explica de forma adequada (LIMA; ANTUNES, et al., 2017a; 2017b). Deve-se observar que os livros apresentam tal fenômeno como saber aceito (enunciado tipo 4) e não mostram as disputas, incertezas e limitações do texto original de Einstein. Eisberg e Resnick afirmam, por exemplo, "Em cada caso, iremos obter evidência experimental que a radiação é como partícula em sua interação com a matéria" (EISBERG; RESNICK, 1985, p. 27) sem discutir como essa "evidência" foi construída.

O "Ensino não moderno", fundamentado na perspectiva de Latour, poderia explicar o argumento utilizado por Einstein (EINSTEIN, 1905) sobre a entropia da radiação para construir a hipótese da quantização da energia, evidenciando que o próprio Einstein colocou sua afirmação como uma hipótese (enunciado tipo 1): “(...) fenômenos conectados com a emissão e transformação da luz são mais prontamente compreendidos se assumimos que a energia da luz é distribuída descontinuamente no espaço" (EINSTEIN, 1905). Mostraria também que Einstein se baseou no modelo de Wien da radiação e não de Planck e que assumiu que seu modelo talvez só fosse válido dentro dos limites de validade do modelo de Wien (enunciado tipo 2). Tal perspectiva ainda discutiria as razões, segundo as quais, durante mais de 20 anos, Einstein foi o único a defender essa posição (MARTINS; ROSA, 2014).

Nesse caso, caberia questionar: se a quantização da radiação é algo tão óbvio, como afirmam os livros atuais, por que ninguém foi convencido por Einstein? Quais recursos semióticos ele usou para convencer seus pares? O que esse episódio histórico pode nos dizer sobre a ciência e sobre a sociedade alemã do início do século XX?

É interessante observar nesse exemplo que os livros didáticos desempenham o papel de consumar o objetivo do cientista de promover os enunciados tipo 1 e 2 a enunciados tipo 5 . Enquanto Einstein afirma apenas conjecturas e faz propostas limitadas, os livros apresentam 
um conhecimento aceito que deve se tornar saber tácito para aquele que o lê. Tal perspectiva de educação científica já fora discutida por Thomas Kuhn, que descreveu o papel dos livros e manuais de instrução (KUHN, 1978) como instrumentos de manutenção das visões hegemônicas da ciência.

Deve-se notar, entretanto, que optar por "abrir a caixa preta" não é só uma questão didática, mas ideológica. Parte do trabalho da ciência é justamente o de apagar os rastros da criação dos fatos científicos, promovendo os enunciados tipo 1 a enunciados tipo 5. Uma Educação em Ciência que privilegie o processo de abertura de caixa preta, dessa forma, está se posicionando ideologicamente contra parte do trabalho da ciência. Isso não significa, contudo, que se está desmerecendo a ciência ou se opondo a ela. Pelo contrário, tal ensino demanda que se entenda que a ciência não é importante porque descobre verdades imutáveis e universais, mas porque articula a realidade através de uma extensa e complexa rede de actantes. Abrir a caixa preta da ciência exige uma mudança radical de perspectiva epistemológica.

Há exemplos de trabalhos na área de educação em ciências que reconhecem que a prática científica excede o seu produto, entendendo a partir da visão latouriana, que a educação científica deve privilegiar outras atividades além do conhecimento conteudista, incentivando a visita em laboratórios científicos (QUEIROZ; ALMEIDA, 2004; VIANNA; CARVALHO, 2001). Complementamos, entretanto, que a simples visita em laboratórios ou mesmo a mimetização de pesquisa científicas, como o tão presente ensino por investigação, só faz sentido quando acompanhada de uma complexa e profunda discussão sobre a natureza da ciência. Sem isso, corre-se o risco de omitir as controvérsias ou de desqualificar o trabalho científico.

\section{VI.2 Estudar os processos e não os produtos - Abandonando o mito do gênio e a univer- salidade dos entes}

O ensino segue privilegiando em seu discurso a noção de descoberta científica individual e não de construção de verdades através de redes sociotécnicas. O mito do gênio é um exemplo de como essa visão ainda é aceita atualmente. Ao invés de criar personagens míticos que descobrem verdades, o ensino pode mostrar como as redes constroem verdades, ressaltando o papel não só dos humanos, mas dos não-humanos. Certamente, para se opor ao mito do gênio, não é necessária a obra de Latour, e outros estudos epistemológicos também fazem essa indicação (ALLCHIN, 2003; 2004). Entretanto, a proposta de híbridos nos lembra que a ciência não é construída somente por um conjunto de humanos, mas por uma rede heterogênea.

Ademais, a visão de Latour traz consequências não somente sobre "a autoria" do fato científico, mas também sobre a essência mutável deste fato (LATOUR, 2013). No caso do fóton, devemos entender que o fóton de Einstein não é o mesmo fóton de De Broglie, e esse, por sua vez, não é o fóton de hoje. Precisamos especificar de qual dos muitos fótons estamos falando. É o fóton da teoria que aparece no formalismo matemático ou de uma inscrição resul- 
tante de um experimento? E mais, qual interpretação se está usando para o fóton? A interpretação realista corpuscular física semi-clássica ou a interpretação realista ondulatória de Schrodinger? A intepretação dualista realista de De Broglie? Ou a interpretação positivista de Copenhague?

Ao explicitar, entretanto, de "qual fóton" estamos falando, estamos evidenciando que o fóton não existe enquanto um ente objetivo, universal e independente. Ele somente existe mediante a articulação de sua rede. Discutir tal relação, mais uma vez, vai de encontro ao esforço da comunidade científico de apagar as ligações entre um actante e a rede que o articulou. Ao adotar uma perspectiva ontológica latouriana, deve-se ter clareza que a Educação em Ciências estará se posicionando axiologicamente de forma contrária à própria atividade científica. Isso não significa, entretanto, se opôr à ciência ou mesmo a desmerecer. Pelo contrário, a Educação em Ciências, ao adotar tal perspectiva, tem a oportunidade de valorizar a ciência pelo que ela faz e não pelo que os epistemólogos absolutistas gostariam que ela fizesse.

\section{VI.3 Apresentação das redes - Revendo a perspectiva CTS na Educação em Ciências}

É muito comum, na área de Educação em Ciências, falarem sobre a necessidade de "contextualizar" o ensino. A forma com que tal implementação vem sendo feita, entretanto, parece sustentar a dicotomia natureza-sociedade exposta por Latour, ou seja, pinta-se um cenário histórico ou sociológico, muitas vezes de forma pitoresca, ao redor do "fato cientifico". Livros didáticos falam, por exemplo, em tom anedótico ou trazem uma suposta contextualização CTS, a qual reforça o mito da linearidade e da superioridade tecnocrática (LIMA; OSTERMANN; CAVALCANTI, 2017)

Assim, muitos educadores entendem que estão fazendo um ensino CTS quando na verdade estão reforçando visões simplistas sobre a ciência. Entendemos que tal proposta deve ser superada. O Ensino CTS deve pautar-se em uma reflexão profunda e consistente sobre a natureza da realidade e da ciência. Não existem respostas simples. Somente e partir dessa visão de mundo é possível discutir relações ciência, tecnologia, sociedade sem recair em posicionamentos ingênuos. Na literatura em Educação em Ciências, encontramos apenas um trabalho em que isso é feito. Faria e Coutiho (2015) analisam o Projeto Apolo utilizando a cartografia das Controvérsias (VENTURINI, 2009).

\section{VI.4 Formar uma tribo de leitores-escritores}

De acordo com LATOUR e WOOLGAR (1988), um dos elementos que caracteriza os cientistas é sua forma peculiar de escrever textos. Um dos objetivos da Educação em Ciências poderia ser, portanto, introduzir os alunos a esse tipo de escrita. Ao invés de submetê-los a listas infindáveis de exercícios algorítmicos, a Educação de Ciências pode voltar-se à prática e ao desenvolvimento da leitura e escrita científica, sem com isso recair em uma perspectiva de ciência objetiva, neutra e universal. Oliveira e Queiroz (2015), por exemplo, elaboraram um mapa de caracterização do texto científico. Uma possibilidade de aplicação didática seria 
a discussão dos elementos textuais presentes nesse mapa e a produção de textos que contemplem tais características.

\section{Considerações finais}

Neste trabalho apresentamos as ideias basilares do pensamento de Bruno Latour, focando, principalmente, em seus pressupostos ontológicos. Tentamos mostrar que Latour se afasta tanto da noção de corte epistemológico de Bachelard como do Programa Forte de Bloor, pois ambos se aliam a algum tipo de visão assimétrica sobre a realidade.

Partindo do conceito de Antropologia Simétrica, mostramos que natureza e sociedade deixam de ser os polos ontológicos que explicam a realidade e se tornam aquilo que deve ser explicado. Quando observamos fenômenos criados em laboratório, por exemplo, estamos diante de um híbrido, um quase objeto resultado de práticas naturais, sociais e discursivas. Olhando para esse híbrido e investigando a rede sociotécnica do qual faz parte podemos investigar e chegar a conclusões sobre o que é a sociedade e o que é a natureza do qual ele faz parte.

Discutimos que a modernidade se fundou negando a existência dos híbridos e da prática de mediação; separando, por consequência, os polos da natureza e da sociedade. Mostramos, entretanto, que, na prática, tal postura não se sustenta, já que o trabalho do cientista é um trabalho de mediação entre os diferentes atores da rede sociotécnica. Com essa visão, interpretamos o Livro A Vida de Laboratório mostrando que Latour faz exatamente o que propõe sua visão não moderna, estudando um híbrido (TRD) e sua rede empiricamente e formulando conclusões sobre o que é a prática científica. Latour descreve os cientistas como leitoresescritores que têm por objetivo convencer seus leitores usando referentes externos.

A partir disso, propusemos a necessidade de uma profunda revisão dos objetivos, dos conteúdos e dos métodos utilizados na Educação em Ciências. Há que se questionar o ensino de teorias fechadas como caixas pretas, na perspectiva da ciência em ação. Um caminho promissor é buscar traçar as redes, observando processos, evitando contextualizações sociais rasas e inúteis, não reificando o contexto social, mas assumindo todo contexto como um cotexto.

\section{Agradecimentos}

Agradecemos ao colega Estevão Luciano Quevedo Antunes Júnior pela contribuição ao artigo bem como aos alunos da disciplina de História da Física e Epistemologia do primeiro semestre de 2017 na Universidade Federal do Rio Grande do Sul.

\section{Referências Bibliográficas}

ALLCHIN, D. Scientific myth-conceptions. Science Education, v. 87, n. 3, p. 329-351, 2003. 
Pseudohistory and Pseudoscience. Science \& Education v. 13, p. 179-195, 2004.

ALSOP , S.; FAWCETT, L. After this nothing happened. Cultural Studies of Science Education, v. 5, p. 1027-1045, 2010.

AQUINO, T. O Ente e a Essência. Porto: Edições Contraponto, 1995.

BACHELARD, G. A filosofia do não. São Paulo: Abril Cultural, 1978.

A Formação do Espírito Científico. Rio de Janeiro: Contraponto, 1996.

BAKHTIN, M. Os Gêneros do Discurso. São Paulo: Editora 34, 2016.

BARNACLE, R.; MEWBURN, I. Learning networks and the journey of 'becoming doctor'. Studies in Higher Education, v. 35, n. 4, p. 433-444, 2010.

BLOOR, D. Sociologie de la logique ou es limites de l'épistemoogie. Paris: Éditions Pandora, 1982.

BUNGE, M. Física e Filosofia. São Paulo: Perspectiva, 2013.

CARSON, R. Silent Spring. Robbinsdale: FAWCETT PUBLICATIONS, 1994.

COLUCCI-GRAY, L. Beyond evidence: a critical appraisal of global warming as a socioscientific issue and a reflection on the changing nature of scientific literacy in school. Cultural Studies of Science Education, v. 9, p. 633-647, 2014.

CREF. Os farasantes pós-modernistas. Disponível em: <https://www.if.ufrgs.br/cref/?area =questions\&id=986>. Acesso em: 23 mai. 2017.

DODICK, J.; ARGAMON, S.; CHASE, P. Understanding Scientific Methodology in the Historical and Experimental Sciences via Language Analysis. Science \& Education, v. 18, n. 8, p. 985-1004, 2008.

EINSTEIN, A. Über einen die Erzeugung und Verwandlung des Lichtes betreffenden heuristischen Gesichtspunkt. Annalen der Physik, v. 17, n. 132, 1905.

EISBERG, R.; RESNICK, R. Quantum Physics of Atoms, Molecules, Solids, Nuclei, and Particles. 2. ed. New York: John Wiley \& Sons, 1985.

ELLIOTT, S.; YOUNG, T. Nature by Default in Early Childhood Education for Sustainability. Australian Journal of Environmental Education, v. 32, n. 01, p. 57-64, 2015 .

FARIA, E. S.; COUTINHO, F. A. Educação científica em ação: a cartografia de controvérsias como prática de cidadania técnico-científica. Caderno de Pesquisa, v. 22, n. 3, p. 133-147, 2015. 
GIL-SALOM, L.; SOLER-MONREAL, C. Interacting with the Reader: Politeness Strategies in Engineering Research Article Discussions. international Journal of English Studies, n. Special Issue, p. 175-189, 2009.

HARMAN, G. Prince of Netwroks: Bruno Latour and Metaphysics. Melbourne: re.press, 2009.

IORIO, J. M.; HAMM, C.; PARNELL, W.; QUINTERO, E. Place, matters of concern, and pedagogy: Making impactful connections with our planet. Journal of Early Childhood Teacher Education, v. 38, n. 2, p. 121-135, 2017.

KIRCH, S. A.; MA, J. Y. The relationship between passibility, agency and social interaction and its relevance for research and pedagogy. Cultural Studies of Science Education, v. 11, n. 4, p. 1103-1113, 2016.

KUHN, T. A Estrutura das Revoluções Científicas. São Paulo: Perspectiva, 1978.

LAKATOS, I. La Metodologia de los programas de investigacion cientifica. Salamanca: Alianza Universidad, 1984.

LATOUR, B. A Relativistic Account of Einstein's Relativity. Social Studies of Science, v. 18, p. 42, 1988.

Pandoras Hope - Essays on the Reality of Science Studies. Cambridge: Harvard University Press, 1999.

Reassembling the Social: An Introduction to Actor-Network Theory. Oxford: Oxford University Press, 2005.

. Ciência em ação: como seguir cientistas e engenheiros sociedade afora. 2. ed. São Paulo: Unesp, 2011.

Jamais Fomos Modernos. 3. ed. São Paulo: Editora 34, 2013.

Biography. Disponível em: <http://www.bruno-latour.fr/biography>. Acesso em: 23 de maio de 2017.

LATOUR, B.; WOOLGAR, S. La vie de laboratoire: la Production des faits scientifiques. Paris: La Découverte, 1988.

A vida de laboratório: a produção dos fatos científicos. Rio de Janeiro: Relume Dumará, 1997.

LIMA, N. W.; ANTUNES, E.; OSTERMANN, F.; CAVALCANTI, C. A História do Fóton em Livros de Física. Enseñanza de las Ciencias, v. extra, p. 1953-1957, 2017a. 
Uma Análise Bakhtiniana dos Enunciados Sobre o Efeito Fotoelétrico em Livros Didáticos do Ensino Superior. Enseñanza de las Ciencias, v. extra, p. 1947-1951, 2017b.

LIMA, N. W.; OSTERMANN, F.; CAVALCANTI, C. Física Quântica no ensino médio: uma análise bakhtiniana de enunciados em livros didáticos de Física aprovados no PNLDEM2015. Caderno Brasileiro de Ensino de Física, v. 34, n. 2, p. 435-459, 2017.

MARTINS, R. D. A.; ROSA, P. S. História da teoria quântica - a dualidade ondapartícula, de Einstein a De Broglie. São Paulo: Livraria da Física, 2014.

MELO, M. D. F. A. D. Q. A pipa e os quatro significados da mediação sociotécnica: articulações possíveis entre a Educação e a Psicologia para o estudo de um brinquedo. Revista Brasileira de Pesquisa em Educação em Ciências, v. 10, n. 2, p. 1-18, 2010.

NELSON, M. Existence. Disponível em: <https://plato.stanford.edu/entries/existence/>. Acesso em: 13 jul. 2017.

OLIVEIRA, J. R. S.; QUEIROZ, S. L. Elaboração de um mapa de caracterização do texto científico: referenciais teóricos e aplicação em destaque. Investigações em Ensino de Ciências, v. 20, n. 1, p. 142-166, 2015.

PALHARINI, L. Conhecimento disciplinar: (im)possibilidades do discurso sobre a problemática ambiental. Pesquisa em Educação Ambiental, v. 2, n. 2, p. 29, 2012.

POPPER, K. Conjecturas e Refutações. 5. ed. Brasilie: Editora Universidade de Brasilia, 2008.

QUEIROZ, S. L.; ALMEIDA, M. J. P. M. DO FAZER AO COMPREENDER CIÊNCIAS: REFLEXÕES SOBRE O APRENDIZADO DE ALUNOS DE INICIAÇÃO CIENTÍFICA EM QUÍMICA. Ciência \& Educação (Bauru), v. 10, n. 1, p. 41-53, 2004.

SARTRE, J. P. Existentialism is a Humanism. New Haven: Yale University Press, 2007.

SHAPIN, S.; SCHAFFER, S. Leviathan and the Air-Pumb. Princeton: Princeton University Press, 1985.

SLEZAK, P. Sociology of Scientif Knowledge and Scientific Education: Part I. Science\&Education, v. 3, p. 30, 1984.

SOKAN, A. D.; BRICMONT, J. Imposturas Intelectuais. 4. ed. Rio de Janeiro: Record, 2010.

SOLBRÆKKE, K. N.; SOLVOLL, B.-A.; HEGGEN, K. M. Reframing the field of gender and nursing education. Gender and Education, v. 25, n. 5, p. 640-653, 2013. 
STETSENKO, A. From relational ontology to transformative activist stance on development and learning: expanding Vygotsky's (CHAT) project. Cultural Studies of Science Education, v. 3, n. 2, p. 471-491, 2008.

STRAUSS, L. La Pensée Sauvage. Paris: Plon, 1962. Race et Histoire. Paris: Danoël, 1987.

TAKAO, A. Y.; KELLY, G. J. Assessment of Evidence in University Students' Scientific Writing. Science \& Education, v. 12, p. 341-363, 2003.

VENTURINI, T. Diving in magma: how to explore controversies with actor-network theory. Public Understanding of Science, v. 19, n. 3, p. 258-273, 2009.

VIANNA, D. A.; CARVAlHO, A. M. P. Do fazer ao ensinar ciência: a importância dos episódios de pesquisa na formação de professores. Investigações em Ensino de Ciências, v. 6, n. 2, p. 111-132, 2001.

WERTSCH, J. Voices of the mind: a sociocultural approach to mediated action. Cambridge: Harvard University Press, 1992.

(c) EY-NC-ND Direito autoral e licença de uso: Este artigo está licenciado sob uma Licença Creative Commons. 